\title{
Intergenerational Networks, Unemployment, and Persistent Inequality in South Africa
}

\author{
Jeremy R. Magruder*
}

July 28, 2009

\begin{abstract}
This paper examines the importance of network-based intergenerational correlations in South Africa. I use longitudinal data on young South Africans to examine the covariance of children's employment with parents' usefulness in job search. I find that fathers serve as useful network connections to their sons (and not daughters), but that mothers do not seem to be useful network connections. The father-son effect is robust to alternate explanations of specific human capital and correlated networks. The size of this effect is large: present fathers' utility as network connections may be responsible for a $1 / 3$ increase in their sons' employment rates.
\end{abstract}

JEL Codes: O12,J62,J21

\section{Introduction}

There are many avenues by which parents can help their children succeed in the labor market. For example, a parent can invest in his child's education, he can provide money to defray search costs, or he can endow his child with a genetic code that is more or less suited to the current labor market. Each of these advantages can lead to reduced societal mobility, and economists have sought to quantify the importance of these sorts of effects for over a

*Department of Agricultural and Resource Economics, University of California, Berkeley, 207 Giannini Hall, Berkeley, CA 94720, e-mail jmagruder@berkeley.edu. I thank Joseph Altonji, Lori Beaman, Fabian Lange, Rohini Pande, Mark Rosenzweig, T. Paul Schultz, Christopher Udry, three anonymous referees, and seminar participants at Berkeley, RAND, Vanderbilt, Williams, and Yale. I gratefully acknowledge support from the Agricultural Experiment Station. All mistakes are naturally my own. 
century, both through isolating individual effects and in total. One avenue which has long been mentioned (since at least Becker and Tomes 1979) but remains relatively unquantified is the importance of parents as network members. That is, parents can provide children with references, job information or social connections which grant an advantage in the labor market much as inherited wealth can. This lack of quantification a significant oversight: parents' roles as network members may be especially important in high unemployment settings, where job information and references represent scarce, valuable commodities, and where low mobility may create poverty traps. Family networks are also concerning as they represent a particularly zero-sum sort of correlation - if intergenerational networks are important, then they serve to reallocate jobs away from one young adult and towards another one, who is better connected but not necessarily more capable.

In South Africa, jobs are truly scarce, especially for the majority black population. Official statistics indicate that $42 \%$ of prime-aged adults were unemployed over the period 2002-2004 ${ }^{1}$. Further, while unemployment has remained high in South Africa since at least the late 1970s, the distribution of the unemployment has changed substantially since the fall of Apartheid. Unemployment durations have become longer, suggesting that economic opportunities are worsening for the unemployed. This decline in mobility seems especially surprising given the increase in de jure economic opportunity available to non-whites after Apartheid ended. Legal changes associated with the end of Apartheid shifted the regime allocating jobs, and anecdotal evidence suggests that networks are now governing job allocation. If the employed provide disproportionate help in job search to a few friends and family members, then the use of network connections to allocate jobs may have contributed to this decline in mobility as some individuals find themselves qualified but socially isolated. An extreme example would be if employed parents serve as particularly useful network connections for their children.

This paper sits at the nexus of the network and intergenerational correlations literatures.

\footnotetext{
${ }^{1}$ These statistics define an individual as unemployed if they are not working but report that they would accept a job.
} 
Using a panel data set of young adults in Cape Town, South Africa, I ask if parents have become important network connections for their children. Unlike past network and intergenerational correlations studies, this approach looks for fluctuations in the ability of parents to provide job information and references to their children. I compare the intertemporal variance in employment numbers in parents' industries with changes in children's labor force behavior. As parents' wealth may be correlated with labor demand in their industries, I take advantage of gender-segregation and geographic specificity in jobs to create two control groups who should experience wealth effects but cannot take advantage of network aid. Estimation reveals that when fathers' industries are hiring, sons are more likely to work if their fathers are in the province, but that sons with absent fathers and all daughters are less likely to work. This negative relationship for individuals whose fathers are not network connections is consistent with the hypothesis that wealth effects are diminishing the labor supply of these young adults. The point estimate is large; when a father's industry grows by $10 \%$, his son is $3-4 \%$ more likely to work if the father is present. In contrast, mothers do not appear to represent effective network connections for either sons or daughters. The father-son effect does not appear to be driven by inherited specific human capital, as children are not similarly sensitive to employment trends in industries which the father no longer works in, nor are they particularly sensitive to occupation-industry trends which may more accurately reflect skills (but not network utility, as one learns of jobs at a plant, not necessarily within an occupation category).

I open this paper by discussing the empirical literatures on intergenerational correlations and networks, and provide a simple example of how networks can exacerbate intergenerational correlations from other sources described in the literature. I then describe in greater detail the institutional structure and the unemployment situation in South Africa, and summarize evidence that networks have supplanted bureaucratic job allocation since the end of Apartheid. Next, using a new panel dataset of young adults in the Cape Town area, I argue that fathers are providing jobs to their sons, but not to their daughters, when they 
live close enough to be able. I then establish that the results are robust to attrition and specific human capital, and that it is fathers (and not other network men) who are useful in this way. I close with a back-of-the-envelope calculation suggesting that father-son networks may increase employment rates by $1 / 3$ for sons with helpful fathers.

\section{Intergenerational Networks and Job Allocation}

A natural lens to study mobility is to examine the ability of parents to determine outcomes for their children - if well-off parents are able to endow their children with labor market advantages, then these intergenerational correlations may hinder the ability of poor children to succeed to their potential. In a seminal paper, Becker and Tomes (1979) discuss the implications of dynastic utility where each generation faces a trade-off between own consumption and the consumption of the next generation, purchased through either investing in human capital or transferring physical capital. Children receive their parents' gifts as well as a "luck" endowment which will be correlated with their parents' endowments. With concave utility, richer parents invest more in their children. Between investment choices which are a function of economic success, gifts, and correlated "luck," several avenues for intergenerational correlation are discussed. Noteworthy to this investigation, Becker and Tomes acknowledge the importance of parental "connections" in intergenerational correlations, but do not explicitly consider them in their model. Theoretical investigations since have followed their example and focused on different mechanisms for intergenerational correlation ${ }^{2}$.

Since Becker and Tomes work, many empirical investigations have sought to disentangle the relative contribution of each of these inputs and to estimate the elasticity of children's permanent income with respect to parents' income. Solon $(1999,2002)$ surveys the literature; these studies find an elasticity of parent's permanent income on their children's on the order

\footnotetext{
${ }^{2}$ For example, Banerjee and Neuman (1993) find that credit constraints can imply an unequal and immobile long-run distribution of wealth if investment opportunities are non-convex, while Mookherjee and Ray (2002) find that credit constraints imply that equality of outcomes is unstable if occupations are diverse simply due to differential optimal investment in children. If families are important as network connections, then the occupation-based effects that these authors highlight will become stronger.
} 
of .2-.4, in both the developed and developing world ${ }^{3}$. Because this literature concerns itself with long term outcomes, it has been unable to isolate the social capital benefits parents may grant their children from correlated other benefits as parents remain constant members of a child's employment network. This lack of attention contrasts sharply with a large literature in economics and sociology, which has found networks to be an important way to transmit job information.

Empirical support for the importance of networks is strong, and is surveyed in Ioannides and Loury (2004). Within the economics literature, empirical work has taken two approaches. In the first, researchers look for random variation in the size of a group who seem likely to be in an individual's network, such as other migrants from the same village (Munshi 2003) or refugees from the same country (Beaman 2009). The second approach looks for correlations in outcomes based on geographical distance of residence, and spatially models those correlations. This approach either compares residential distance to other distance metrics (e.g. Conley and Topa 2002) or compares individuals who live very close together to those who merely live nearby (e.g. Bayer, Ross and Topa 2005). Both approaches arrive at the conclusion that having the group whom you are likely to know be more numerous or better off helps in job search.

We can conclude from this literature that networks are an important job allocation mechanism. However, we haven't learned very much about specific relationships which may be important to job allocation within a network. Due to data limitations and endogeneity concerns, the existing empirical network literature has focused on finding groups of individuals correlated with the "true" effective networks relevant to individuals, either through geographic or ethnic proximity, rather than identifying the effect of actual network members ${ }^{4}$.

\footnotetext{
${ }^{3}$ Similar or slightly larger correlations are also found world wide if we examine intergenerational correlations in education rather than earnings (Hertz et al 2007) with a stable correlation of .4; Thomas (1996) estimates a similar correlation for South Africa.

${ }^{4}$ One effort to correct for mismeasured networks is in Munshi and Rosenzweig (2003). They condition on father's occupation to be sure that the sub-caste (and not family) is the right unit of analysis in their study on sub-caste level networks in India. In that study, they find that father's occupations are significant determinants of young adult outcomes, but that it is unrelated to sub-caste networks.
} 
As a result, we can say with some confidence that individuals in a network become better off on average when a network improves in some way, for example with an infusion of job information. However, we do not know the distribution of these gains, and it is possible that the gains are concentrated among small, closely related groups, as is suggested in intergenerational correlations models. The potential for complicated, relationship-specific heterogeneity in the diffusion of jobs through networks makes it very difficult to assess the overall implications of networks for mobility, and impossible through a strategy which observes only correlated networks ${ }^{5}$. If we isolate instead the role of a few individually important network connections, we can learn how some types of social connections contribute to mobility and inequality, though such an approach cannot describe all effects of the universe of social connections.

In fact, there is some indication that a few closely related family members are especially important social connections, particularly in high-unemployment settings. Granovetter (1983) surveys empirical evidence from sociology which finds that disadvantaged groups in the US are more likely to use close relationships to find employment. Loury (2006), finds that 10 percent of US men found jobs through prior generation male relatives, representing

\footnotetext{
${ }^{5}$ A simple example illustrates the importance of relationships in job diffusion for mobility: networks $a$ and $b$ both consist of $N$ individuals, subdivided into families of $K$. In network $a$, the family is irrelevant; individuals pass job information at random to other network members. In network $b$, only family members are network members; individuals pass job information on only to other family members. In period $t$, fraction $p$ of adults are working, and working adults hear about jobs with probability $\alpha$. For simplicity, jobs are never destroyed. In network $a$, everyone is equally mobile: each period, $N p \alpha$ new jobs are learned of and divided among $N(1-p)$ individuals, so every unemployed person has probability $p \alpha /(1-p)$ of learning of a job. In the long run, everyone becomes employed in network $a$. In network $b$, each unemployed person's probability of learning of a job depends on the fraction of people in his family who are working; that is, if $F$ people in his family are working, than he has probability $F \alpha /(K-F)$ of learning of a job. Clearly, unemployed people in fully unemployed families have no chance of finding employment, while unemployed individuals in a highly employed family are likely to find employment before long. Even in the long run, some families remain completely unemployed, while others become fully employed. Mobility implications in this example are immediate: not only are long run opportunities better in network $a$ than in network $b$, unemployed individuals face more equal chances of employment. That is, unemployed individuals in high-employment families in network $b$ have very good chances of being employed in the next period, while unemployed individuals in low or zero employment families in network $b$ have very poor or zero chances of becoming employed. In contrast, everyone in network $a$ faces the same chance of finding a job, which rests between these two extremes. Though the assumptions in this example are extreme, the intuition carries through if individuals only treat their families with preference, that is, if they are more likely to tell family members about jobs than unrelated network members.
} 
more than $1 / 5$ of all network help, and suggesting that a few family nodes matter. She finds that young women almost never receive job offers from male contacts, and as these referrals from older male relatives are the only type of network help which results in higher wages, women are being excluded from network aid. In a job-rich environment like the US, wages are the relevant indicator of a valuable network, and her results are qualitatively similar to mine. Finally, Kramarz and Skans (2006) investigate whether Swedish children are more likely to get a job at the same plant as their parents than their classmates are. They find a strong effect, particularly in high-unemployment and low-skill settings. However, since their interest is in a one-time event (the first stable job received by these young adults), they are unable to perfectly control for factors which are doubtless correlated between parents and children, such as geographical location, specific human capital, preferences, and abilities.

\section{$2.1 \quad$ Model}

A simple adaptation of Becker and Tomes (1979) model (adapted via Solon 1999) suggests the importance of networks for intergenerational mobility. Parents in generation $g-1$ face a choice over their consumption and investment in their children in generation $g$. Working individuals receive a wage equal to their human capital; for simplicity human capital is unrelated to experience. Parents have Cobb-Douglass utility over their own consumption and the consumption of their child,

$$
U\left(C_{g}, C_{g-1}\right)=\alpha \ln \left(C_{g}\right)+(1-\alpha) \ln \left(C_{g-1}\right)
$$

The parent's budget constraint is

$$
y_{g-1}=H_{g-1} \sum_{t} W_{g-1, t}=C_{g-1}+I_{g}
$$

$W_{g-1, t}$ is an indicator indicating whether parents are working in time $t$, and they receive a wage of their human capital $H_{g-1}$ if working. They spend that wage on their own 
consumption and investment in their children, $C_{g-1}$ and $I_{g}$.

In turn, the young adult finds himself with human capital $r I_{g}+E_{g}$, where $E_{g}$ is his luck endowment and $r$ the annualized return on invested human capital. Over his lifetime, he therefore earns

$$
y_{g}=\left(r I_{g}+E_{g}\right) \sum_{t} W_{g t}
$$

Where $r$ represents the rate of return on human capital investment and $E_{g}$ the error in human capital for generation $g$. Naturally, both of these only result in income when the young adult is working, $W_{g-1, t}=1$. The first order conditions quickly lead to the optimal investment choice, $I_{g}=(1-\alpha) y_{g-1}-\frac{\alpha}{r} E_{g}$. With Cobb-Douglass utility, investment choices are not related to the future labor force behavior of the child (as long as $\sum_{t} W_{g t}>0$ ); in a more general model the parent may consider his son's future work opportunities in making investment choices.

Next, I allow for network effects, by modeling generation $g$ 's labor force status.

$$
W_{g t}=\gamma_{1} W_{g-1, t}+u_{g t}
$$

where $\gamma_{1}$ is the probability that a working parent in generation $g-1$ learns of a job ${ }^{6}$. If parents are important network connections, $\gamma_{1}>0$. If not, $\gamma_{1}=0$. Using the optimal investment choice, we can rewrite equation 2 as

$$
y_{g}=(1-\alpha)\left(r y_{g-1}+E_{g}\right) \sum_{t}\left(\gamma_{1} W_{g-1, t}+u_{t g}\right)
$$

Solon's description of this model focuses on the term $(1-\alpha)\left(r y_{g-1}+E_{g}\right)$, and the motivations for intergenerational correlation that he considers are contained within it. In contrast, network based correlations are shown to be multiplying this effect, which is logical: if parents' income resembles their children's due to any correlation in human capital, this

\footnotetext{
${ }^{6} \gamma_{1}$ can be thought of as the random job offer rate discussed in Calvo-Armengol and Jackson (2004).
} 
capital can only earn a return when it is being exercised, i.e. the individual in question is working. That is, all of the constraints to economic mobility reviewed in the literature are exacerbated in the presence of intergenerational networks. ${ }^{7}$

\section{Unemployment and Labor Markets in South Africa}

The context for this study is South Africa, where unemployment is both severe (with a steady $42 \%$ broad unemployment rate from 2002-2004 among 20-60 year old adults ${ }^{8}$ ) and heavily concentrated among the young and blacks. The cause of this unemployment is hotly debated, and discussed more extensively in a series of papers by Kingdon and Knight (e.g. 2004, 2006, 2008). This paper does not contribute to that debate, but a few institutional suspects emerge and are relevant to job allocation. First, formal sector wages in South Africa are very high compared to per capita income, due to governmental policies which encourage capital-intensive production (Seekings and Nattrass 2005), collective bargaining (e.g. Moll 1996, Schultz and Mwabu 1998) and extensive labor regulation. These high wages may affect unemployment through job shortages (Magruder 2009), search, or voluntary mechanisms, and large governmental transfers similarly may cause voluntary unemployment (Bertrand, Mullainathan, and Miller 2003). Secondly, unlike other countries with similar official employment rates, the informal sector is small overall (Kingdon and Knight 2006). Similarly, few adults are engaged in subsistence agriculture (only 14\% of the 2003 population reports any farming activity), due in part to the consolidation and mechanization of agriculture under Apartheid. The reasons why the entrepreneurial informal sector remains so small despite

\footnotetext{
${ }^{7}$ In this example, network capabilities are unrelated to income. However, introspection and existing literature suggests that there may be some relationship. A more general model would make this explicit and $\gamma_{1} W_{g-1, t}$ would be replaced by $\Gamma\left(y_{g-1, t}, W_{g-1, t}\right)$. One might in principle imagine $\Gamma(\cdot)$ to be positively or negatively correlated with income, as high income managers have more control over hiring decisions while conventional wisdom suggests that close relations are more important in (potentially lower paid) blue collar jobs. While a complicated $\Gamma(\cdot)$ could in principle cause networks to either increase or decrease intergenerational correlations, the basic intuition that networks change the structure of intergenerational correlations goes through regardless of the wealth derivatives of $\Gamma$.

${ }^{8}$ These, and other labour statistics in this section are taken from the statistical releases associated with the September Labour Force Surveys described below. Broad unemployment counts all individuals who do not have a job but would accept one as unemployed.
} 
high unemployment (and vigorous survey efforts to find $\mathrm{it}^{9}$ ) is unclear, and may be due to legal barriers (Kingdon and Knight 2004), job search, or other explanations. Whether by choice or by restriction, unemployment appears to be the default outcome of most individuals who do not find formal sector jobs.

We can best understand mobility in this context by examining how likely it is for an unemployed person to find employment. If, for example, turnover was very high, then unemployed individuals may not be substantially disadvantaged in their future income prospects relative to those who are currently employed and hence (relatively) wealthy. In South Africa, however, employment prospects of the currently unemployed are bleak. Among the prime-aged broadly defined unemployed in 2003, 77\% have not worked in at least 3 years, including $58 \%$ who have never held a job. This represents a substantial deterioration in mobility in the 10 years following Apartheid: in 1993, the corresponding figures were $62 \%$ who had not worked in three years, and $52 \%$ who had never worked. Unsurprisingly, then, post-Apartheid South Africa has been associated with poverty traps (Adato et al 2006) and increasing inequality (Aguero et al 2008).

There has been a great expansion of employment freedoms in the same time period, and it is rather striking that the liberalized markets that characterize South Africa today seem to more effectively exclude some adults than did the bureaucratic regime which existed prior to 1993. Under Apartheid, all employment opportunities for rural blacks were funneled through local bureaucracies (including the right to work, to search for work, and choice of work sectors), and laws of job reservation (by which particular categories of jobs were reserved for different racial groups) similarly restricted the opportunities available to coloureds and urban blacks (Seekings and Nattrass 2005). This system began to break down in the 1980s. Anecdotal evidence suggests that this bureaucratic job allocation was supplanted by social networks; a 1996 survey of manufactures reported that when $41 \%$ of firms report need to fill

\footnotetext{
${ }^{9}$ The South African Labour Force surveys contain a battery of questions about different types of work that they may have done "even for only one hour," including unpaid work in a household business, farming for subsistence, begging, etc. Despite this effort, very few people report any behavior resembling the commonplace informal economic activity found in other developing countries.
} 
vacancies, they hire friends and relatives of employees (Standing, Sender, and Weeks 1996).

If household or family networks are now solving the information problems endemic to liberalized labor markets, these may be compromising the ability of different groups to take full advantage of the labor market opportunities. Seekings and Nattrass (2005, p. 282) discuss the distributional implications of using network channels for job allocation in greater detail: "It is surely the case that the number of discouraged unemployed in South Africa is large in part because vacancies are so often filled using [network] channels. Thus it is likely that, among the unemployed, there are some with good prospects for employment and others with poor prospects and that the former are more likely to be members of households with working members." This argument is one of network scale: if household members (or worse, only fathers) are allocating many of the jobs in South Africa, individuals with low quality households are themselves disadvantaged. Indeed, if networks are now regulating employment in South Africa, we may expect that parents would preserve the scarce jobs they have access to for their children for both selfish and altruistic reasons. Examining intergenerational correlations induced by networks is thus central to analyzing the South African labor market.

\section{Empirical Strategy}

Fixed effects will be central to my analysis on the probability of working. As such, I use a linear probability model to avoid the incidental parameter problem, and abuse notation to ignore the latent variable nature of the binomial working decision in the same way that the model does ${ }^{10}$. Suppose that a parent in family $f$ in generation $g-1$ works in industry

\footnotetext{
${ }^{10} \mathrm{~A}$ more complete model would allow young adults to choose between working, schooling, and leisure, rather than merely the binomial choice of working or not. The only multinomial choice model which avoids the incidental parameter problem is Chamberlain's (1980) multinomial conditional logit. However, the independence of irrelevant alternatives assumption limits the utility of considering the multinomial choice if our concern is that schooling opportunities may bias coefficients. Moreover, as the individual fixed effects are not identified in this model, consistent marginal effects cannot be determined, and the specification has less power than the linear probability model considered here. Nonetheless, results of this procedure (available from the author) are similar to those in the linear probability model. Schooling coefficients are opposite in
} 
$i$ at time $t$. If we model a parent's utility in job search as the sum of the offer rate in his industry $\left(\gamma_{1} \phi_{i t}\right)$, a parent-specific fixed effect $\left(\xi_{f g-1}\right)$, and an exogenous error term $\left(\nu_{f g-1, t}\right)$, and allow a child's likelihood of working to depend also on parent income $\left(y_{f g-1, t}\right)$, some covariates $\left(X_{g t}\right)$, child and time fixed effects $\left(\xi_{f g}+\delta_{t}\right)$, and his own error term, $\left(\nu_{f g t}\right)$ then the empirical analogue to equation 3 is

$$
W_{f g t}=\gamma_{1} \phi_{i t}+\gamma_{2} y_{f g-1, t}+\beta X_{f g t}+\xi_{f g}+\xi_{f g-1}+\delta_{t}+\nu_{f g-1, t}+\nu_{f g t}
$$

Taking fixed effects at the individual level eliminates the parent and son time-invariant effects, $\xi_{f g}$ and $\xi_{f g-1}$, and generates the primary estimation.

However, two immediate concerns need to be addressed. First, the offer rate in an individual industry is unobserved. In practice, I use log employment in the Western Cape Province in the two digit industry that the parent is working in at baseline to proxy the offer rate, with unemployed fathers registered as having 0 employment in their industry in all three years of the survey. In even the simplest model, employment is a function both of labor supply and labor demand. Hence if industry-specific labor supply increases, we would expect employment in that industry to increase. Simultaneity is not a concern as individual labor supply decisions are too small to impact provincial employment statistics. Trends in overall labor supply are picked up by the time trends utilized, and time-constant individual labor supply components are captured by the fixed effects. Nonetheless, I will be picking up labor supply effects if innovations in industry-specific labor supply are correlated with the industry in which one's parent works (at baseline). That is, if sons of construction workers tend to want work in construction but not manufacturing more in 2004 relative to 2003 (and sons of manufacturing workers do not), then labor supply is contaminating my estimates. I assume that this is not the case, that is, that trends in industry-specific labor supply are uncorrelated with the industry in which parents are employed at baseline ${ }^{11}$. Baseline sign from the working ones, though never significant

${ }^{11}$ An alternate approach is an instrumental variables strategy suggested by Bartik (1991) and Blanchard and Katz (1992). These authors argue that the local share of a national industry is more or less fixed over 
industries (rather than current industries) are forced by data limitations on non-coresident fathers; however, this approach is desirable in any event as baseline industry analysis is insensitive to unobserved industry-specific heterogeneity, which becomes absorbed in the fixed effect. The use of baseline industries does mean that I will have the wrong employment series for fathers who change industries during the panel; this type of measurement error should cause attenuation bias.

Even if I could observe the offer rate perfectly I would face the problem that parent income will be correlated with this offer rate. In practice, I do not observe parent income if they do not live in the household, which creates an omitted variable problem in the above specification. To address this issue, I follow an approach similar to Duflo and Saez (2002) and Munshi and Myaux (2006) in contrasting within-demographic group effects, where social interactions should be the highest, to between-group effects. In South Africa, a natural intra-household group is gender. In fact, if the relationship between the offer rate and employment represents network effects, then there are three reasons that we may think that these correlations are segregated by gender. First, there is good reason to believe that social interactions are strongest within demographic groups (Duflo and Saez 2002, Munshi and Myaux 2006). Second, gender-specificity is known to be important in intrahousehold relationships in South Africa (Duflo 2000, Bertrand, Mullainathan, and Miller 2000), which, combined with the previous insight suggests that father-son and mother-daughter pairs may have the strongest social ties. Finally, and perhaps most importantly, jobs are quite gendersegregated in South Africa. As a descriptive statistic, I calculate the fraction of black and coloured employees who are female in each 3-digit industry, and then examine the distribution

time, and that industry supply trends are more local while labor demand trends are more national in nature. If so, then taking the average provincial share of an industry and multiplying that by national employment rates gives an estimate of labor demand in the industry. Here, I use the average ratio of local employment to employment in the other eight provinces over my study period, and multiply employment in the other provinces by that rate. This approach (available from the author) yields similar, though noisier, results to the OLS, and the male-female difference remains identified. Moreover, a regression-based Hausman test (Wooldridge 2002) does not give an ex ante reason to prefer the instrumented estimates over the OLS, lending credence to the identification assumption. An additional advantage of this estimation is that it is immune to the sampling error concerns discussed in the appendix (as sampling error is independent across provinces), and grants reassurance that the baseline effect is not generated by sampling error. 
of the fraction of female workers in an industry by the gender of workers (that is, so that we observe the density of the fraction of female employees that male employees face). Figure 1 presents kernel densities for both men and women using the September 2003 Labour Force Survey; as is apparent, men tend to work in male dominated industries while women tend to work in female-dominated industries. Here, the degree of gender segregation is large. The median male worker works in an industry which is $70 \%$ male, while the median female worker works in an industry which is $2 / 3$ female $^{12}$. The job openings that fathers are likely to learn about are thus jobs that tend to be staffed by men. Daughters therefore, may serve as a control group who will experience father's wealth effects, but have lower access to the father's social networks as a means of finding jobs.

However, we may be concerned that sons are different from daughters in their sensitivity to offer rates for other reasons. A second control group, therefore, is generated by the geographic specificity of jobs - one cannot accept a job at a plant at a location too distant from where one lives (at least without moving and disappearing from the data, and the reported results are robust to this sort of attrition). In Cape Town, many children have parents working in other provinces, who may still remit money but cannot provide access to jobs. Therefore, both sons and daughters whose fathers live in a different province should not be affected by job information, and only affected by the correlated implications for the fathers. This allows a triple-differenced approach, where we ask how sons of present fathers differ from daughters of present fathers in terms of their sensitivity to employment trends, and use sons and daughters of absent fathers as a control group to hold constant any differences between sons and daughters which is not driven by network concerns ${ }^{13}$.

\footnotetext{
${ }^{12}$ Note that this result isn't completely mechanical: While it's true that males must work, on average, more in male-dominated industries than females, the bulk of the mass for each gender does not need to be concentrated at the extremes. In particular, if all industries employed equal fractions men and women, we would observe all of the mass for each gender at the 50 percent line.

${ }^{13}$ We may be concerned that children of absent fathers are an imperfect control for two reasons. First, absent fathers may remit a different portion of their income to children than present fathers. Second, the choice of which employment series to use for absent fathers is non-obvious: the motivating income story would seem to be more closely related to the employment series in the father's province of (baseline) residence, which can be constructed for most of the sample. On the other hand, children in the sample actually become employed in the Western Cape province, so many stories which would relate child employment to
} 
Moreover, since daughters should not experience network effects from fathers, we can test directly whether children of absent parents are a good control group, by examining whether daughters whose fathers live nearby appear different than those whose fathers live away in terms of sensitivity to trends in father's industries. Symmetric tests can be considered for mothers and daughters versus mothers and sons, although data limitations discussed below eliminate the possibility of maternal proximity as a test. All regressions that follow are conditional on individual, age, and year fixed effects.

\section{Data}

The Cape Area Panel Study ${ }^{14}$ (Lam et al 2006) is a random sample of 4758 young adults aged 14-22 in 2002 who live in the Cape Town Metropolitan Area. These young adults were interviewed first in 2002. A subset of 1360 young adults were reinterviewed in 2003, with the remainder reinterviewed in 2004, and all were reinterviewed in 2005 . At each interview after 2002, a monthly calendar of past behavior was collected, allowing the creation of a full panel with all behavioral variables (e.g. working, schooling enrollment) taken to be behavior in September of that year (chosen to coincide with the labor force surveys described below). Attrition is a problem in this study, due to the migratory behavior of these young adults; $11 \%$ of these young adults disappear before data can be recorded for September 2003 and $26 \%$ before data can be recorded for September 2004. Attrition was especially problematic for the whites in this sample, where $22 \%$ were lost by the end of the 2003 and $44 \%$ by 2005

these employment series (e.g. sectoral labor demand/supply trends, specific human capital, etc.) are better captured in using the local employment series. However, these two series are almost collinear (correlation coefficient $=.97$ ), which both reassures us that the choice of employment series should not be too important and makes it difficult to interpret coefficients when both series are included (in practice, the coefficient and standard error on the variable of interest stay very similar in baseline estimation). Preference is given here for the difference-in-differences approach of using the employment series in the child's province, both for ease of interpretation and as income appears to have a negative effect on employment for both sons and daughters anyway. The key idea in this analysis is that we shouldn't expect sons with present fathers to be different from their male peers with absent fathers in terms of sensitivity to employment trends in a way that daughters are not.

${ }^{14}$ The Cape Area Panel Study Waves 1-2-3 were collected between 2002 and 2005 by the University of Cape Town and the University of Michigan, with funding provided by the US National Institute for Child Health and Human Development and the Andrew W. Mellon Foundation. 
(many of these moved out of country, most of the rest out of the Western Cape province). Due to the substantial attrition in the white sample, I restrict my analysis to blacks and coloureds; $10 \%$ of these people are lost to attrition by the end of 2003 and $23 \%$ by 2005 . I examine the effects of attrition in robustness analysis below.

Table 1 reports summary statistics for this sample. Few of these young adults are working, with only $25 \%$ of males and $18 \%$ of females employed. This difference largely reflects the difference in the percentage of men and women who found jobs through networks; 6 or $7 \%$ of both men and women found jobs through their own means (e.g. applying at factories, sending out CVs), whereas $14 \%$ of men compared to $8 \%$ of women found a job after a network member told them about it or referred them for it. Also worth noting is that many of these young adults have fathers who are either deceased or do not live in the province, and that many of those with fathers in the province do not cohabit with the father at baseline. The geographical heterogeneity within families is due in part to the migration restrictions which were lifted only at the end of Apartheid, so that many in this sample are recent migrants. As a large urban area, Cape Town is a destination for migration, so absent fathers are often either those who have not migrated yet or who have returned to their more rural homeland area. Fewer young adults have mothers who live away, though this still represents a large fraction of my sample. Industries of employment will be central in the analysis that follows. In the Web Appendix, I describe the construction of provincial employment data ${ }^{15}$.

\subsection{Intergenerational Correlations in Industries}

If parents procure jobs for their children through social connections, we should observe children being systematically likely to work in the same industries as their parents. Here,

\footnotetext{
${ }^{15}$ As with any macroeconomic indicators constructed from survey data, these employment series are subject to sampling error, suggesting that a Murphy and Topel (1985) correction may be useful. Preference in this paper is given to clustering the errors, however, as the Muphy-Topel correction is found to be very small in this case, and failing to account for serial correlation in difference in difference estimates may yield much larger biases (Bertrand, Duflo, and Mullainathan 2004).
} 
I adopt a test for intergenerational correlations in industry, similar to Altonji and Dunn (1991). I run systems of seemingly unrelated regressions, where each dependent variable is a dummy for working at baseline in a one-digit industry and the right hand side consists of dummies for the father or mother being in that industry, and a dummy for the father or mother working, along with race, age, and education fixed effects. The point estimates from this test are presented in figure 2, while the test is presented in more statistical detail in the appendix. For each industry, each bar reveals the coefficient of having a parent in that industry on a working child's presence there. Figure 2 reveals that, for most industries, a father's presence in an industry is associated with working sons being about 7-12\% more likely to work in that industry, and working daughters being about $2 \%$ more likely (the sons' coefficients are additionally jointly different from zero while the daughters' are not). Mothers industries in contrast, are more strongly related to daughters industries (also around 7-12\% for most industries, again jointly distinct from zero only for the same gender $)^{16}$.

If intergenerational networks are important, and there is a gender component to the operation of these networks, we should anticipate that sons are more likely to be employed when their fathers' industry is doing better (and daughters may not be). A simple figure can summarize this idea: here, I detrend log employment in fathers' industries ${ }^{17}$, and rank industry-years of employment in terms of their growth over the previous year. For each industry-year, I then calculate the detrended employment rate for sons and daughters who work in that industry. Figure 3 presents a kernel-weighted local polynomial smoother of these changes in average employment rates of children versus the growth percentile of their fathers' industry-year (the bandwidth is 15). Since these data are detrended the median industry-year has a 0 growth rate in employment. For these industry-years, both sons and daughters of fathers who work in these industries can expect no change in their average

\footnotetext{
${ }^{16}$ Performing a similar exercise reveals that occupational correlations are smaller, not jointly significant and without the same gender pattern, a fact explored further in the appendix. This fits well with the network story, as job information is spread across occupations within a plant rather than within occupations, which will be used when exploring the specific capital explanation below.

${ }^{17}$ As above, this is log employment in the Western Cape Province for the father's baseline two-digit industry
} 
employment status. For industry-years better than the median, sons expect to see their employment status increase, while daughters expect a contraction; the opposite is true in years in which industries shrink relative to the median. While standard error bars on these images are large, a linear analogue to this specification rejects both the hypotheses that sons' employment is unrelated to the rank of their father's industries and that the daughters experience the same effect as sons.

\section{Estimation Results}

Table 2 reports the results of estimating equation 4 for fathers. Columns 1 and 2 report average effects for sons and daughters separately, and confirms that sons are more likely to be working when their fathers' industries are growing, while daughters are less likely to. Column 3 puts all young adults together, and identifies that only sons with present fathers are more likely to work when their fathers' industries grow. The point estimate is quite large: if employment increases by $10 \%$ in a father's industry, then the son is $3 \%$ more likely to work if his father is nearby. Sons whose fathers live away and all daughters are negatively effected by increases in fathers' employment trends, consistent with the hypothesis

of a negative wealth effect on labor supply. Daughters whose fathers live away look the same as those whose fathers live in the province, in contrast to sons, suggesting that children of absent parents are a good control group. Further, the joint test for a male coefficient is very precisely estimated (as is the joint test for a female coefficient). Agricultural parents may be different than others; though all children in the sample are metropolitan Cape Town residents, their children may be more rural than other children. This may limit their employment opportunities to agriculture and violate the identification assumption on labor supply. As such, column 4 excludes these young adults and finds no difference in the identified network effect.

A further test of the theory is to examine the difference between jobs received through 
network connections and those found through young adults' own effort. Though unfortunately I cannot observe exactly who got the job for the young adult, I can differentiate between young adults who received jobs through network connections (they report either that a household member or friend or relative outside of the household told them about the job or got them the job at their workplace) and those who found jobs through sending out CVs or inquiring at factories. In columns 5 and 6 of table 2, I replace the dependent variable with an indicator which is equal to one if the young adult is both working and found the job through either the network or his or her own effort. As column 5 indicates, sons with present fathers are more likely to work in a job found with network help when their fathers' industries are growing, while column 6 indicates that they are no more likely to work in a job acquired through their own means ${ }^{18}$. Consistent with negative wealth effects felt by all children, everyone is less likely to find work on their own when their fathers' industries are expanding, though this estimate is only marginally significant.

An additional extension tests whether sons are more likely to be working in their fathers' industries when those industries are expanding. It is true that young men with present fathers are much more likely to work in their fathers' two-digit industry than other young adults: $11.5 \%$ of young men with present fathers who ever work do so in their fathers' two-digit industry at least sometimes, which contrasts with $4.7 \%$ of young women with present fathers who ever work, $2.2 \%$ of young women with absent fathers, and only a single young man with an absent father (out of 216 young men with absent fathers who ever work). This speaks to the importance of network effects in getting these jobs, though geographical differences in industry composition may confound this interpretation and suggest a more careful test. However, the empirical model developed above is not well suited to this problem. Young adults face a nested decision: they may work or not, and if they work they may work in a variety of industries. These industrial choices are no doubt related to job availability, and

\footnotetext{
${ }^{18}$ The sample changes slightly in columns 6 and 7 due both to some non-response in the question on how a job was found and some difficulty in matching jobs contained in the calendars of past behaviors with this variable. Running the baseline regression on this different sample (omitted for space concerns) produces virtually identical results to the full sample.
} 
we may imagine that the father's access to jobs affects both his son's working decision and industrial choice ${ }^{19}$. Estimating a simple linear probability model on working in the father's industry sounds initially promising; however, the misspecification in such a test would cause a bias towards zero for several reasons. First, we lose the capacity of daughters and sons of absent fathers to serve as control groups for anything which effects the working decision but not industrial choice. Year-to-year fluctuations in wealth, in particular, likely belong to this category; as these are associated with less working throughout this paper, they seem likely to cause a conservative bias in this specification. Second, we do not observe whether a job is offered, only whether one is accepted. As jobs in other industries are close substitutes for jobs in the fathers' industries, individuals who miss out on an available job in the fathers' industry because they are otherwise employed will lead to this (incorrect) linear specification finding smaller effects.

As suggestive evidence, I break young adults into sons and daughters and ask how each of these groups respond to employment trends in their fathers' industries, restricting attention to young adults with present fathers (as so few young adults with absent fathers work in their fathers' industries). Since we lose the ability of other groups to serve as controls for wealth effects, I look only at the average employment trends, with the caveat that any wealth effects remaining are likely causing a conservative bias. To test whether some differences may be due to other job offers, I ask whether this response is different in two subgroups which seem less likely to have competing offers: in one specification, I omit young adults who worked in an industry other than their father's in the previous year, while in a second, I omit young men and women who live in sampling clusters where at least 30 percent of the young adults of the same gender in other households in that cluster are employed. This requirement eliminates the top $1 / 3$ of sampling cluster-year observations in terms of gender-

\footnotetext{
${ }^{19}$ The "correct" empirical model to test this hypothesis would be a nested logit or something similar; however, to the author's knowledge there is no such procedure which can allow for fixed effects with such a short panel (and the IIA assumption needed for logit models in general seems very likely to be violated in this case, in any event). In principle, the analysis on jobs found through networks or by oneself is also subject to these concerns, though as there are only two choices in that case (as opposed to 46 industries which young adults work in), the bias caused by the nested multinomial choice is likely to be smaller.
} 
specific employment rates ${ }^{20}$. Panel A of table 3 reveals that in all estimations, sons are more likely to be working in their fathers' industries when those industries are expanding, while daughters are never differentially likely to work in the father's industry. Estimated effects are larger and statistically significant if we exclude sons who seem likely to have offers from other jobs, consistent with the hypothesis that the young adults who are most affected by job offers from their fathers are those with the least access to alternative job offers. Panel B of this table excludes agricultural fathers, and finds that all effects are larger in magnitude and more precisely estimated, which is reassuring given doubts on the identification assumption for agriculture.

I next test whether mothers serve a similar role. Caution must be taken with this analysis, as very few mothers both live in a different province and are actually working. In fact, there are only 30 young men and 24 young women whose mothers live in a different province and who have time-variance both in their own labor force status and in employment in their mother's industry, which makes the Mothers' here-away comparison highly sensitive to individual outliers, and potentially attrition problems (which is differentially high among children of absent mothers). As a result of these data limitations, I restrict the analysis of mothers to average son and daughter effects for children with mothers in the province, though results are similar if absent mothers are included.

Table 4 reports coefficients from similar linear probability models to the baseline. There is no discernible effect on daughters of changes in mothers industries. In fact, the coefficients on sons appears larger than daughters and reaches marginal significance, though it is smaller than the father-son effect. Mothers have even smaller effects on the likelihood of network employment. Moreover, in all cases, the effects become much smaller and stay insignificant once agricultural mothers are excluded (even columns of the table), leaving little to suggest

\footnotetext{
${ }^{20} 0.3$ is kept for consistency across genders and is actually a little bit above the 67 th percentile for young womens' employment; that is at a 0.25 employment rate and results are robust to using this alternate cutoff. Interestingly, and providing reassuring support given the gender-segregation of labor markets, males who live in clusters where young women have fewer employment opportunities have similar coefficients to those in the full sample (unlike males in clusters with low male employment rates), while young women have a similar response in both groups of clusters.
} 
that this is the same network effect found for fathers given the concerns about the identification assumption for agriculture. The analysis concludes that South African daughters do not benefit from their mothers as network connections, which recalls Loury's (2006) absence of a wage boost for women who get jobs with help from their older female relatives. A potential explanation for this difference is that women work in different industries than men in South Africa. These industries may simply rely less heavily on networks, either due to some technological differences or the relative scarcity and informality of these jobs. In fact, sons who work in the basket of industries that mothers work in are about equally likely to report network help as daughters in those industries, and are less likely to report network help than sons who work in the basket of industries that fathers work in. This suggests that something about these industries may render them less suitable for network help ${ }^{21}$.

\section{Robustness}

Three main challenges to identification stand out. First, there is extensive attrition in this survey, and it is important to verify that the estimated results are not derived from attrition-based sample selection. Second, an alternate explanation for the trend highlighted is that fathers endow their sons with human capital specific to a given industry, so that their labor force behavior reacts differentially to trends in that industry without network effects. Finally, fathers may be one of many useful network connections for sons, and if these network members work in similar industries, it could deliver this result with fathers themselves being extraneous. I test whether these correlated networks could deliver these results or if fathers themselves are important.

\footnotetext{
${ }^{21}$ Daughters are not similarly advantaged by working in the industries that fathers work in, however, suggesting that a gender component is important as well.
} 


\subsection{Attrition}

Attrition is important in this survey, and it is possible that attrition is correlated with network effects as I have estimated them, though the individual fixed effects used in the analysis would eliminate any time-invariant differences. In fact, some of the attrition may even be causal and part of what I attempt to estimate- while fathers who live away are useless sources of job information for sons who remain in Cape Town, they may be helping out sons who disappear from my sample, because they might move to be with their fathers. Indeed, as Panel B of table 1 reports, attritors are more likely to have fathers living in other provinces than non-attritors at baseline, although their fathers tend to be much less employed as well. To test if attrition could be responsible for my results, I adopt two approaches, both presented in the appendix. The first is a test similar to Becketti et al (1988), which uses baseline data to test whether relationships between the explanatory variables of interest and the dependent variable are similar in the attrition and non-attrition sample. The second makes a variety of extreme assumptions on attritors' behavior ${ }^{22}$ and tests the sensitivity of estimation to these extreme assumptions. The data easily passes the Becketti et al test, and the second approach reveals that even if attritors behave in extreme ways, the coefficient pattern is unaffected in sign, in magnitude, or (in all cases but one) precision. These tests suggest that attrition is not responsible for the trend highlighted in this paper.

\subsection{Specific Human Capital}

If young adults inherit industry-specific human capital from a lifetime of learning from their fathers which makes them specifically qualified or desiring to work in the same industry as their fathers, then their employment will react strongly to labor demand in that industry without network effects (and the identifying assumption on labor supply may be incorrect). The CAPS dataset allows a direct test of this hypothesis. Specifically, respondents are

\footnotetext{
${ }^{22}$ In particular, I assume in turn that all attritors are working; that none are; that those with present fathers are and those with absent fathers are not; and the opposite.
} 
queried about the industry that their father worked in "most of the time [while] you were growing up" in addition to the question of what industry fathers are working in now. Unsurprisingly, these variables are correlated, but there is substantial variation; many fathers moved in and out of employment, and among those who were employed in both periods, $44 \%$ switched industries. If industry-specific preferences or human capital is driving these results, we would expect that to be correlated with employment trends in fathers' historical industries as well as their current ones. That is, whatever learning or genetic process leads to this human capital, it seems likely to have occurred at earlier ages as well and so young adults should also be sensitive to employment trends in industries that the father used to work in. Column 2 of Table 5 reports this test on a male only sample and we find that conditioning on log employment in the fathers' historical industry does not impact the parameters of interest, nor is it itself significant. This suggests that industry-specific human capital is not driving the network effects observed in the baseline estimates.

However, specific capital may not be industry-specific. In particular, the very reasons that we find fathers working in different industries now relative to the past may be that a new industry is now better rewarding the capital which the father and son share. A natural classification of skills which are rewarded differentially in different industries is occupation, so the above argument would suggest that the family-specific human capital is now being especially rewarded in the occupation-industry cell that fathers are currently working in. In contrast, networks need not be occupation-specific; a father can learn of or give reference for any opening at the plant he works, not simply the ones in his occupation. Table 5 explores this possibility by aggregating occupations in two ways. In column 3 , I use a very coarse characterization of occupation, where occupations are divided into skilled white collar, unskilled white collar, and blue collar, while column 4 allows employment at the one-digit occupation within an industry level. Columns three and four reveal that the relevant effect is at the industry, not the occupation-industry level, suggesting that specific human capital is not behind this effect. 


\subsection{Correlated Networks}

Another potential problem could exist if fathers' industries are correlated with other industries in a young adult's network. That is, your father is someone who often lives in your neighborhood, and someone who often lives in your household. These networks may have nothing to do with paternity and rather be attributable to randomly selecting adults who are close to these young adults. In Cape Town, men other than the father often serve as the head of household, and the CAPS data includes sampling cluster identifiers (clusters are neighborhoods of about a 3 block radius) allowing us to ask whether sons respond only to trends in their fathers' industries or trends in the industries of other men in their household or sampling cluster. This exercise (available on the web appendix) reveals that the strong network effect remains on fathers who live in the province after controlling for trends in other industries, and the point estimate remains similar and significant. In contrast, head of household effects are negative and hover around marginal significance, much as the father's employment trend on daughters and sons of absent fathers does. This provides further support to the wealth effect hypothesis - it appears that young men get wealth support from male heads of household who are not their fathers, but do not benefit from network connections. Young adults are additionally not sensitive to employment trends in the modal industry of neighborhood men, and the father-network effect is similarly unaffected by including the employment rate among young men and women in the sampling cluster as a control variable for neighborhood trends. These two results together highlight the importance of correctly identifying network members in network studies, as different network members operate in very different ways.

\section{Conclusions}

Fathers are important network connections for sons in South Africa. The fixed effects analysis, however, makes it difficult to determine the extent to which intergenerational networks 
impact inequality, as, by definition, the variable of interest is mean zero for each individual. One possibility is to presume that the fixed effects covary with industry demand in such a way that employed fathers are just as useful in their industry's worst year as unemployed fathers are in that year. Note that this assumption implies that each employed father's network connections are as useless as an unemployed father's in one year of the study. Under this assumption, each industry has 2 years with which to reward the sons of working, present fathers, and in each of these two years industries are on average .3 log points above their minimum. Given the point estimates above, this suggests that sons with present, working fathers work on average about .18 years more than daughters or sons of unemployed or absent fathers over the sample period. In the estimation sample, $20.7 \%$ of person-years are spent working; if networks increase working by .06 per year for those who can use them this would suggest a gain of $1 / 3$. The plausibility of this effect size is borne up through simple means. In the estimation sample, the sons of employed, present fathers work in $26.3 \%$ of personyears, while others work in $19.5 \%$. Based on the above back-of-the-envelope calculation, father-son networks may be responsible for $6 / 7$ of this difference. In other words, intergenerational networks can explain nearly all employment inequality between sons of present, employed fathers, and other young adults. Since $55 \%$ of black and coloured young men in this region have absent, unemployed, or deceased fathers, this suggests that the majority of these young adults are at a large disadvantage. Moreover, those with present fathers are already advantaged: estimation sample households with present, working fathers have, on average, about $70 \%$ more income than those without at baseline, and are also advantaged in terms of education and IQ test scores. At the same time, young women do not appear to benefit from these network connections.

The importance of networks forces the immediate (and not uncontroversial) conclusion that unemployment in South Africa is not entirely voluntary - unless jobs are truly scarce, variations in labor demand should not be affecting young adults differentially. The long term prognosis is severe: a characteristic which the majority of young adults do not have and can 
not obtain is very helpful for employment. Indeed, a limitation of this study is that this problem is so severe that there are no easy policy recommendations, and government may be forced to adopt creative policy. For example, the South African government could encourage the spread of job information and try to prevent discrimination against unconnected, qualified individuals through anti-nepotism laws. More certainly, the policy implication of this work is that the luxury of using government policy to sustain high wages at the cost of high unemployment is very costly. Rather than simply creating unemployment, these policies create long run poverty traps which are inherited by children.

Finally, this study emphasizes the importance of studying social connections at a disaggregate scale. It appears that fathers are individually important network connections for sons. If network connections are ignored in intergenerational correlations models, this effect will (at best) be left as residual inexplicable similarity, and at worst be correlated with an effect of interest. Moreover, if a few close social connections are individually important, then some jobs and network benefits may exist disproportionately among close-knit groups and not reach many individuals in a network. This study has an immediate implication for survey design: if investigators want to understand heterogeneity in network effects, the development of survey instruments to capture individual network members is an important priority.

\section{References}

Adato, M., M. Carter, and J. May (2006): "Exploring Poverty Traps and Social Exclusion in South Africa Using Qualitative and Quantitative Data," Journal of Development Studies, pp. 226-247.

Aguero, J., M. Carter, and J. May (2008): "Poverty and Inequality in the First Decade of South Africa's Democracy: What Can Be Learned from Panel Data From KwaZuluNatal?," Journal of African Economies, 16(5), 785-812.

Altonji, J. G., And T. Dunn (1991): "Relationships Among the Family Incomes and Labor Market Outcomes of Relatives," Research in Labor Economics, 12, 269-310.

Banerjee, A. V., And A. F. Newman (1993): "Occupational Choice and the Process of Development," The Journal of Political Economy, pp. 274-298. 
Bartik, T. J. (1991): Who Benefits from State and Local Economic Development Policies? W.E. Upjohn Institute for Employment Research, Kalamazoo, Michigan.

Bayer, P., S. Ross, and G. Topa (2008): "Place of Work and Place of Residence: Informal Hiring Networks and Labor Market Outcomes," Journal of Political Economy, 116(6), 1150-1196.

Beaman, L. A. (2009): "Social Networks and the Dynamics of Labor Market Outcomes: Evidence from Refugee Resettlement," http://faculty.wcas.northwestern.edu/ lab823/.

Becker, G. S., And N. Tomes (1979): "An Equilibrium Theory of the Distribution of Income and Intergenerational Mobility," The Journal of Political Economy, 87(6), 11531189.

Becketti, S., W. Gould, L. Lillard, and F. Welch (1988): "The Panel Study of Income Dynamics After Fourteen Years: An Evaluation," Journal of Labor Economics, $6(4), 472-492$.

Bertrand, M., E. Duflo, and S. Mullainathan (2004): "How Much Should We Trust Difference-in-Differences Estimates?," Quarterly Journal of Economics, 119(1), 249-275.

Bertrand, M., S. Mullainathan, and D. L. Miller (2003): "Public Policy and Extended Families: Evidence from Pensions in South Africa," World Bank Economic Review, $17(1), 27-50$.

Blanchard, O. J., and L. F. Katz (1992): "Regional Evolutions," Brookings Papers on Economic Activity, 1992(1), 1-75.

Calvo-Armengol, A., and M. O. Jackson (2004): "The Effects of Social Networks on Employment and Inequality," The American Economic Review, 94(3), 426-454.

Chamberlain, G. (1980): "Analysis of Covariance with Qualitative Data," The Review of Economic Studies, 47(1), 225-238.

Conley, T., and G. Topa (2002): "Socio-Economic Distance and Spatial Patterns in Unemployment," Journal of Applied Econometrics, 17(4), 303-327.

Duflo, E. (2003): "Grandmothers and Granddaughters: Old-Age Pensions and Intrahousehold Allocation in South Africa," World Bank Economic Review, 17(1), 1-25.

Duflo, E., And E. SAEz (2002): "Participation and Investment Decisions in a Retirement Plan: The Influence of Colleagues' Choices," Journal of Public Economics, 85(1), 121-148.

Granovetter, M. (1983): "The Strength of Weak Ties: A Network Theory Revisited," Sociological Theory, 1, 201-233.

Hertz, T., T. Jayasundera, P. Piraino, S. Selcuk, N. Smith, and A. VerashchagINA (2007): "The Inheritance of Educational Inequality: International Comparisons and Fifty-Year Trends," The B.E. Journal of Economic Analysis and Policy, 7(2), (Advances). 
IoAnnides, Y. M., And L. D. Loury (2004): "Job Information Networks, Neighborhood Effects, and Inequality," Journal of Economic Literature, 42(4), 1056-1093.

Kingdon, G. G., And J. Knight (2004): "Unemployment in South Africa: The Nature of the Beast," World Development, 32(3), 391-408.

(2006): "The Measure of Unemployment When Unemployment is High," Labour Economics, 13(3), 291-315.

(2008): "Unemployment in South Africa, 1995-2003: Causes, Problems, and Policies," Journal of African Economies, 16(5), 813-848.

Kramarz, F., and O. N. Skans (2006): "Nepotism at Work? Family Networks and Youth Labor Market Entry," Unpublished.

Lam, D., J. Seekings, and M. Sparks (2006): The Cape Area Panel Study: Overview and Technical Documentation for Waves 1-2-3. The University of Cape Town.

Loury, L. D. (2006): "Some Contacts are More Equal Than Others: Informal Networks, Job Tenure, and Wages," Journal of Labor Economics, 24(2), 299-318.

Magruder, J. R. (2009): "High Unemployment Yet Few Small Firms: The Role of Centralized Bargaining in South Africa," mimeo, University of California, Berkeley.

Moll, P. (1996): "Compulsory Centralization of Collective Bargaining in South Africa," The American Economic Review, 86(2), 326-329.

Mookherjee, D., And D. RAy (2002): "Is Equality Stable?," The American Economic Review, 92(2), 253-259, Papers and Proceedings of the One Hundred Fourteenth Annual Meeting of the American Economic Association.

Munshi, K. (2003): "Networks in the Modern Economy: Mexican Migrants in the U.S. Labor Market," The Quarterly Journal of Economics, 118(2), 549-599.

Munshi, K., And J. Myaux (2006): "Social Norms and the Fertility Transition," Journal of Development Economics, 80(1), 1-38.

Munshi, K., And M. Rosenzweig (2003): "Traditional Institutions Meet the Modern World: Caste, Gender, and Schooling Choice in a Globalizing Economy," BREAD Working Paper 038.

Murphy, K. M., and R. H. Topel (1985): "Estimation and Inference in Two-Step Econometric Models," Journal of Business and Economic Statistics, 3(4), 370-379.

Schultz, T. P., and G. Mwabu (1998): "Labor Unions and the Distribution of Wages and Employment in South Africa," Industrial and Labor Relations Review, 51(4), 680-703.

Seekings, J., and N. Nattrass (2005): Class, Race, and Inequality in South Africa. Yale University Press, New Haven and London. 
Solon, G. (1999): "Intergenerational Mobility in the Labor Market," in The Handbook of Labor Economics, Vol. 3A, ed. by O. Ashenfelter, and D. Card, pp. 631-660. ElselvierNorth Holland, New York.

(2002): "Cross-Country Differences in Intergenerational Earnings Mobility," Journal of Economic Perspectives, 16(3), 59-66.

Standing, G., J. Sender, and J. Weeks (1996): The South African Challenge: Restructuring the South African Labor Market. International Labour Organisation, Geneva.

Statistics South Africa (Producer) (1993): October Household Survey, 1993. South African Data Archive (distributor). www.nrf.ac.za.

(2002-2004): "South Africa Labour Force Surveys, September 2002, September 2003, September 2004," Pretoria, South Africa. South African Data Archive (distributor). www.nrf.ac.za/sada.

Thomas, D. (1996): "Education Across Generations in South Africa," The American Economic Review, 86(2), 330-334.

Wooldridge, J. M. (2002): Econometric Analysis of Cross Section and Panel Data. MIT Press, Cambridge, Massachusetts, and London. 
Table 1: CAPS Summary Statistics

\begin{tabular}{lcccccc}
\hline Panel A & \multicolumn{3}{c}{ Males } & \multicolumn{3}{c}{ Females } \\
& mean & std. dev & $\mathrm{N}$ & mean & std. dev. & $\mathrm{N}$ \\
\hline Black & 0.488 & 0.500 & 4977 & 0.513 & 0.500 & 6063 \\
Age & 18.701 & 2.608 & 4977 & 18.766 & 2.553 & 6063 \\
Father in Province & 0.661 & 0.473 & 4977 & 0.638 & 0.481 & 6063 \\
Father in Household & 0.452 & 0.498 & 4977 & 0.397 & 0.489 & 6063 \\
Father Works & 0.480 & 0.500 & 4977 & 0.468 & 0.499 & 6063 \\
Working & 0.244 & 0.429 & 4977 & 0.178 & 0.383 & 6063 \\
Enrolled & 0.556 & 0.497 & 4967 & 0.558 & 0.497 & 6049 \\
Years of Education & 9.900 & 5.189 & 4894 & 10.528 & 5.274 & 5946 \\
Search Method: & & & & & & \\
Network & 0.143 & 0.350 & 4919 & 0.091 & 0.288 & 6022 \\
No Help & 0.093 & 0.291 & 4919 & 0.083 & 0.275 & 6022 \\
\hline Panel B & Non-Attitors in 2002 & Attritors in 2002 \\
& mean & std. dev & $\mathrm{N}$ & mean & std. dev & $\mathrm{N}$ \\
\hline Black & 0.471 & 0.499 & 3224 & 0.702 & 0.458 & 879 \\
Age & 17.733 & 2.463 & 3224 & 18.499 & 2.413 & 879 \\
Father in Province & 0.670 & 0.470 & 3224 & 0.490 & 0.500 & 879 \\
Father in Household & 0.442 & 0.497 & 3224 & 0.268 & 0.443 & 879 \\
Father Works & 0.482 & 0.500 & 3224 & 0.418 & 0.493 & 879 \\
Working & 0.164 & 0.370 & 3224 & 0.150 & 0.357 & 873 \\
Enrolled & 0.643 & 0.479 & 3222 & 0.501 & 0.500 & 878 \\
Years of Education & 9.559 & 4.769 & 3224 & 9.777 & 6.131 & 878 \\
female & 0.544 & 0.498 & 3224 & 0.588 & 0.492 & 879 \\
Search Method: & & & & & & \\
Network & 0.121 & 0.326 & 3223 & 0.112 & 0.316 & 873 \\
No Help & 0.047 & 0.212 & 3223 & 0.041 & 0.199 & 873 \\
\hline Notes & & & & & &
\end{tabular}

Notes

1 Data from estimation sample of black and coloured young adults.

2 Search methods of "Network" and "No Help" are equal to 1 if the respondent is both working and found a job through the means described, and a zero otherwise.

3 Samples change slightly due to non-response. 
Table 2: Baseline results - Fathers

\begin{tabular}{|c|c|c|c|c|c|c|}
\hline & (1) & $(2)$ & $(3)$ & $(4)$ & $(5)$ & $(6)$ \\
\hline Job Search Method & Any & Any & Any & Any & Network & No Help \\
\hline Log Employment, & $0.087^{* *}$ & $-0.065^{* *}$ & -0.041 & -0.024 & 0.029 & $-0.088^{*}$ \\
\hline Father's Industry & $(0.036)$ & $(0.029)$ & $(0.060)$ & $(0.079)$ & $(0.047)$ & $(0.053)$ \\
\hline Male* & & & -0.134 & -0.162 & $-0.274^{*}$ & 0.141 \\
\hline Father's Industry Employment & & & $(0.116)$ & $(0.125)$ & $(0.153)$ & $(0.092)$ \\
\hline Father in Province* & & & -0.03 & -0.021 & -0.047 & 0.032 \\
\hline Father's Industry Employment & & & $(0.067)$ & $(0.085)$ & $(0.054)$ & $(0.057)$ \\
\hline Male*Father in Province* & & & $0.304^{* *}$ & $0.298^{* *}$ & $0.357^{* *}$ & -0.062 \\
\hline Father's Industry Employment & & & $(0.125)$ & $(0.135)$ & $(0.159)$ & $(0.098)$ \\
\hline Gender & Males & Females & Both & Both & Both & Both \\
\hline Excluding Agricultural Fathers? & No & No & No & Yes & No & No \\
\hline Joint test: Sons & & & 7.28 & 4.25 & 3.49 & 4.13 \\
\hline p-value & & & 0.001 & 0.014 & 0.031 & 0.016 \\
\hline Joint test: Daughters & & & 2.9 & 0.97 & 0.42 & 4.27 \\
\hline p-value & & & 0.055 & 0.381 & 0.628 & 0.014 \\
\hline Observations & 4977 & 6063 & 11040 & 10870 & 10941 & 10941 \\
\hline Number of Individuals & 1830 & 2272 & 4102 & 4037 & 4102 & 4102 \\
\hline R-squared & 0.06 & 0.05 & 0.05 & 0.05 & 0.02 & 0.05 \\
\hline
\end{tabular}

Notes

1 Presents OLS estimates. In columns (1) through (4), the dependent variable is an indicator for working. In column (5), it is an indicator for working in a job found through network help, while in column (6), it is an indicator for working in a job found without aid.

2 Standard errors are clustered at the household level.

3 All regressions are conditional on age, year, and individual fixed effects, and the father's industry is fixed to be his baseline industry. 
Table 3: Working in the same industry as your father

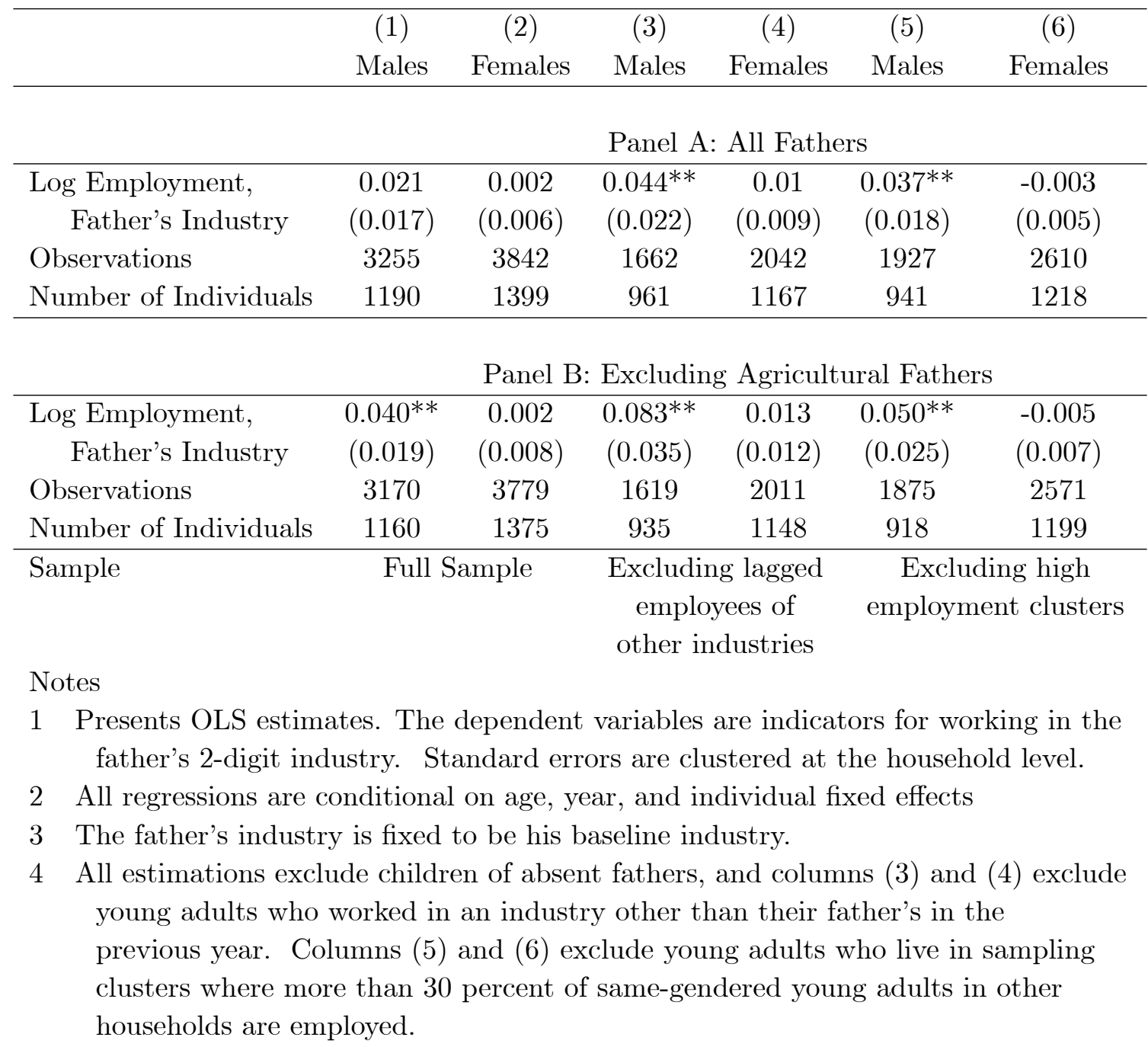




\section{Table 4: Impact of Mothers on Child Employment}

\begin{tabular}{|c|c|c|c|c|c|c|}
\hline & (1) & $(2)$ & $(3)$ & $(4)$ & $(5)$ & $(6)$ \\
\hline Job Search Method & Any & Any & Network & Network & No Help & No Help \\
\hline Log Employment, & -0.048 & -0.047 & -0.031 & -0.032 & -0.011 & -0.009 \\
\hline Mother's Industry & $(0.034)$ & $(0.038)$ & $(0.030)$ & $(0.035)$ & $(0.027)$ & $(0.031)$ \\
\hline Male* & $0.110^{*}$ & 0.059 & 0.067 & 0.035 & 0.023 & 0.011 \\
\hline Mother's Industry Employment & $(0.058)$ & $(0.057)$ & $(0.050)$ & $(0.052)$ & $(0.041)$ & $(0.043)$ \\
\hline Excluding Agricultural Mothers? & No & Yes & No & Yes & No & Yes \\
\hline Observations & 8983 & 8888 & 8901 & 8808 & 8901 & 8808 \\
\hline Number of Individuals & 3243 & 3206 & 3243 & 3206 & 3243 & 3206 \\
\hline R-squared & 0.05 & 0.05 & 0.02 & 0.02 & 0.05 & 0.05 \\
\hline
\end{tabular}

Notes

1 Presents OLS estimates. In columns (1) and (2), the dependent variable is an indicator for working. In columns (3) and (4) it is an indicator for working in a job found using network help. In columns (5) and (6) it is an indicator for working in a job found without aid.

2 All columns exclude absent mothers, and even columns exclude mothers who work in agriculture.

3 Standard errors are clustered at the household level.

4 All regressions are conditional on age, year, and individual fixed effects, and the mother's industry is fixed to be her baseline industry. 
Table 5: Specific Capital and Child Employment

\begin{tabular}{|c|c|c|c|c|}
\hline & (1) & (2) & (3) & (4) \\
\hline Log Employment, & $-0.184^{*}$ & -0.171 & -0.195 & -0.17 \\
\hline Father's Industry & $(0.111)$ & $(0.113)$ & $(0.141)$ & $(0.141)$ \\
\hline Father in Province * & $0.280^{* *}$ & $0.297 * *$ & $0.310^{* *}$ & $0.292^{* *}$ \\
\hline Father's Industry Employment & $(0.117)$ & $(0.121)$ & $(0.147)$ & $(0.148)$ \\
\hline $\begin{array}{l}\text { Log Employment, } \\
\text { Father's Historical Industry }\end{array}$ & & $\begin{array}{l}-0.033 \\
(0.055)\end{array}$ & $\begin{array}{l}-0.032 \\
(0.055)\end{array}$ & $\begin{array}{l}-0.031 \\
(0.055)\end{array}$ \\
\hline $\begin{array}{l}\text { Father in Province * } \\
\text { Historical Industry Employment }\end{array}$ & & $\begin{array}{l}-0.033 \\
(0.067)\end{array}$ & $\begin{array}{l}-0.033 \\
(0.067)\end{array}$ & $\begin{array}{l}-0.035 \\
(0.068)\end{array}$ \\
\hline Coarse Occupation Employment & & & $\begin{array}{c}0.03 \\
(0.092)\end{array}$ & $\begin{array}{l}-0.016 \\
(0.108)\end{array}$ \\
\hline $\begin{array}{l}\text { Father in Province* } \\
\text { Coarse Occupation Employment }\end{array}$ & & & $\begin{array}{c}0.002 \\
(0.094)\end{array}$ & $\begin{array}{c}0.02 \\
(0.110)\end{array}$ \\
\hline Fine Occupation Employment & & & & $\begin{array}{c}0.099 \\
(0.073)\end{array}$ \\
\hline Father in Province * & & & & -0.048 \\
\hline Fine Occupation Employment & & & & $(0.078)$ \\
\hline joint test: Father's Industry & 4.84 & 5.78 & 4.56 & 4.69 \\
\hline p-value & 0.01 & 0.00 & 0.01 & 0.01 \\
\hline Joint test: Specific Capital & & 1.62 & 1.67 & 2.02 \\
\hline p-value & & 0.20 & 0.16 & 0.06 \\
\hline Observations & 4977 & 4977 & 4977 & 4977 \\
\hline Number of individuals & 1830 & 1830 & 1830 & 1830 \\
\hline R-squared & 0.06 & 0.06 & 0.06 & 0.06 \\
\hline
\end{tabular}

Notes

1 Presents OLS estimates. An indicator for working is the dependent variable in each specification.

2 Historical industry employment is current employment in the industry in which your father worked "while you were growing up."

3 Coarse occupations are divided into high-skilled white collar, low-skilled white collar, and blue collar, while fine occupations are at the one digit level. Occupation Employment is log employment in the occupation-industry cell.

4 Standard errors are clustered at the household level.

5 All regressions are conditional on age, year, and individual fixed effects, and the father's industry is fixed to be his baseline industry. 


\section{Figure 1: Fraction Female Employees, 2003}

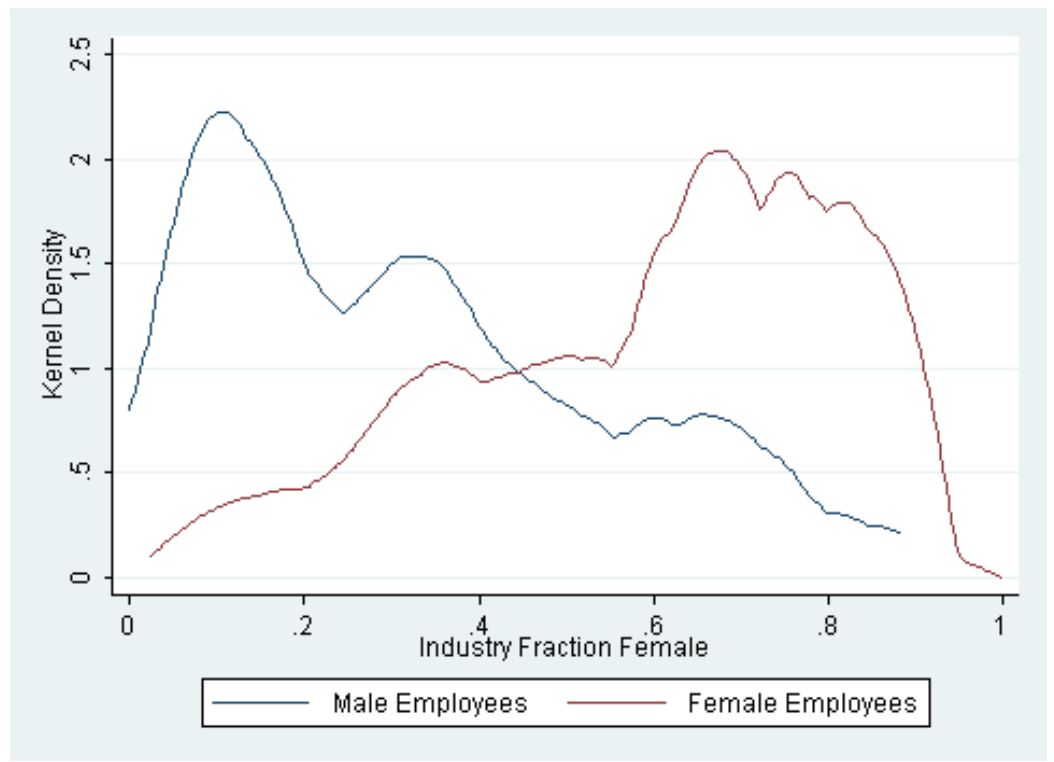

Figure 2: Intergenerational Correlations in Industry

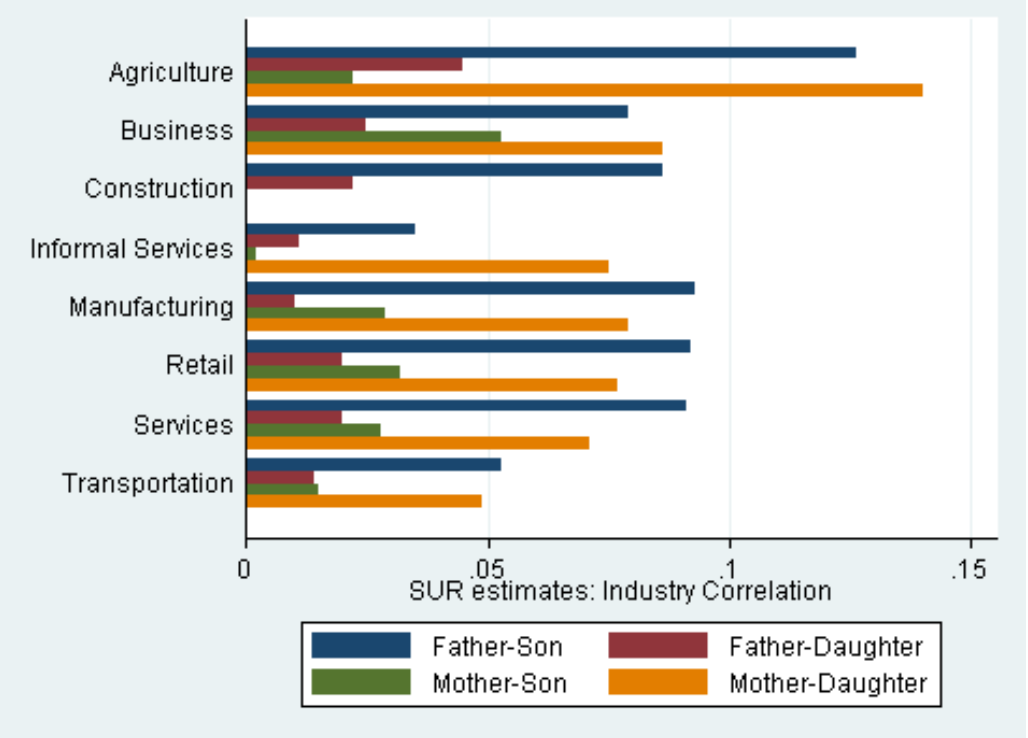


Figure 3: Child Employment and Father's Industrial Growth

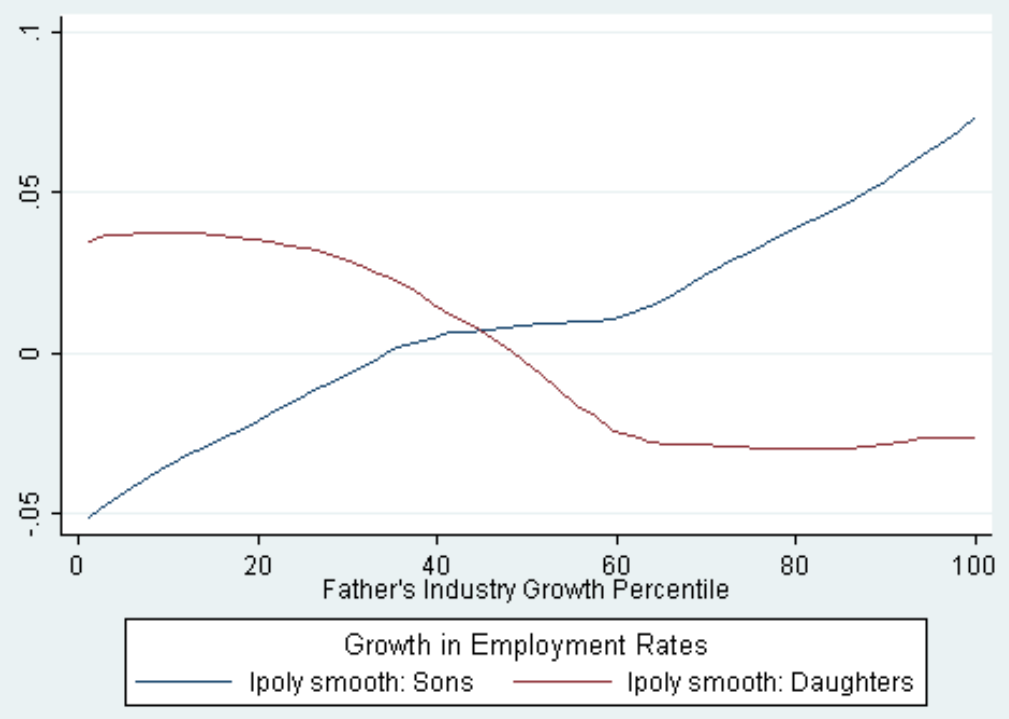

